\title{
The Second International Conference on Reaction Kinetics, Mechanisms and Catalysis
}

\section{Gábor Lente ${ }^{1}$}

Accepted: 27 January 2022 / Published online: 4 February 2022

(c) Akadémiai Kiadó, Budapest, Hungary 2022

The first 11 articles in this issue are based on research that was presented at the 2nd International Conference on Reaction Kinetics, Mechanisms and Catalysis between 20 and 22 May, 2021. The first meeting of the same name was organized in 2018 [1] in Budapest, and it was planned to be biennial. However, as with a great many scientific meetings, the world-wide pandemic interfered and the conference was postponed by a whole year. Even then, it was organized in a fully online format making great use of the web-based environment Whova. The technical center was in Budapest again, but travel was not necessary at all. I believe the use of this advanced service was a first-time experience for most of the participants.

The first lecture was delivered by Angelika Brückner of the Leibniz Institute for Catalysis, who gave a superb example on how to master the potentials of such online lectures. Other plenary speakers were David F. Anderson (University of Wisconsin), Željko Čupić (University of Belgrade), Ferenc Joó (University of Debrecen), Maya Mincheva (Northern Illinois University), Casian Pantea (West Virginia University), András Sápi (University of Szeged), Matteo Signorile (University of Turin), and Aleksey Vedyagin (Boreskov Institute of Catalysis). In the diverse program, 104 researchers from 27 countries presented 58 oral lectures and 30 online posters.

I very much hope this new format of the meeting was met by the approval of the participants, but also trust that the third meeting in this series will be at least partially a personal one.

\section{Gábor Lente}

Editor-in-Chief

\section{Gábor Lente}

reac@gamma.ttk.pte.hu

1 Editorial Office, Reaction Kinetics, Mechanisms and Catalysis, Department of General and Physical Chemistry, University of Pécs, Pécs, Hungary 


\section{Reference}

1. Lente G (2019) The first international conference on reaction kinetics, mechanisms and catalysis. Reac Kinet Mech Cat 126:575-576

Publisher's Note Springer Nature remains neutral with regard to jurisdictional claims in published maps and institutional affiliations. 